\title{
Descartes and the dissolution of life
}

Barnaby R. Hutchins

ABSTRACT: I argue that Descartes is not a reductionist about life, but dissolves or eliminates the category entirely. This is surprising both because he repeatedly refers to the life of humans, animals, and plants and because he appears to rely on the category of life to construct his physiology and medicine. Various attempts have been made in the scholarship to attribute a principled concept of life to Descartes. Most recently, Detlefsen (forthcoming) has argued that Descartes "is a reductionist with respect to explanation of life phenomena but not an eliminativist with respect to life itself' $(4-5)$. I show that all these attempts either result in arbitrariness or force Descartes's wider philosophical project into incoherence. I argue that Descartes's ontological commitments make a principled concept of life impossible, that he does not need such a concept, and that his project ends up more coherent without one.

KEYWORDS: Descartes; reductionism; eliminativism; life; concept

\section{Introduction}

When it comes to the natural world (the world of material substance), Descartes very explicitly positions himself as a strict reductionist: there is matter in motion, and absolutely nothing more (Principles I/48). It might appear that this works well enough when he discusses vortices or rainbows, and explains them in terms of efficient causation between minute particles of matter (although even these cases are not always straightforward). ${ }^{\mathrm{I}}$ It starts to look more problematic when he employs terms that, on the face of it, do seem to

\footnotetext{
${ }^{\text {I }}$ See Hutchins (forthcoming a) on the limits of this corpuscular mechanism in Descartes's physiology.
} 
require something more than matter in motion. We see this, as the literature has pointed out, in the apparent teleology implicit in Descartes's use of functio, usus, or office. ${ }^{2}$ We also see it when he talks about life (vita, vie).

Life ought not to be a category for Descartes. For the scholastics, to whom Descartes was responding on this issue, the vegetative soul could do the work of distinguishing ontologically between the animate and the inanimate: whatever had a vegetative soul was alive; whatever did not was not. This avenue was not open to Descartes. His ontology allows for only one kind of soul, which consists of thinking and absolutely nothing more-and animating a body is not, on his understanding, a kind of thinking (to Regius, May I64I; AT III: 37I). Consequently, in Descartes's ontology, there should be no more of a "difference between living and lifeless things than there is between a clock or other automaton on the one hand, and a key or sword or other non-self-moving appliance on the other" (to Regius, June I642; CSMK: 2I4; AT III: 566). In other words, life can have no special ontological distinction.

And yet Descartes persists in referring to "life" and to "living things." He does not "deny life to animals" (to More, 5 February I649; CSMK 366; AT v, 278). He admits that severed heads that "continue to move about and bite the earth" are "no longer alive" (Discourse 5; CSM I, I39; AT VI, 55; my emphasis). He repeatedly brings up his own "principle of life"-a

\footnotetext{
${ }^{2}$ See, e.g., Brown (20II), Canguilhem ([1965] I980), Des Chene 200I (\$6.I, II7f.), Distelzweig (2015), Simmons 200I, and Shapiro 2003 .
} 
material, Cartesian alternative to the Aristotelian vegetative and sensitive souls. ${ }^{3}$ And in the letter to Regius quoted above, he goes on to say that,

[s]ince 'self-moving' is a category with respect to all machines that move of their own accord, which excludes others that are not self-moving, so 'life' may be taken as a category which includes the forms of all living things

(to Regius, June I642; CSMK: 214; AT III: 566).

So, although life ought not to be a category for Descartes, he appears to make it one. The problem is that, as both MacKenzie (I975: 2-3) and Detlefsen (forthcoming: 9) point out, Descartes never provides a general concept of life. Given that his metaphysics does not allow him an ontological differentiation, it is not at all clear how the category of life can possibly be defined within his philosophical system. Just as it struggles with teleology, a purely material, mechanical ontology seems to lack the resources to separate out living creatures from the rest of the material world.

In what follows, I first assess the various suggestions for a Cartesian concept of life as found in the literature $(\$ 2)$. There has been a series of systematic attempts to unearth a principled concept of life for Descartes, starting with MacKenzie (I975), who builds on some ideas from Hall (I970). The task is taken up again by Ablondi (I998) and then by Detlefsen (forthcoming). All take Descartes to have a general, principled concept of life, and each sees him as a reductionist, in one way or another, about that concept. They take him to reduce life to some thing, or to some set of things, in the material world (for Ablondi and Detlefsen, God also has a role to play in the reduction). Each of these articles shows how

\footnotetext{
${ }^{3}$ E.g. in the Treatise on Man (AT XI, 2O2) and the Treatise on the Passions of the Soul (I:6; AT XI: 33O-I). See Bitbol-Hespériès (I990) for an extensive treatment; Hutchins (forthcoming b) argues that Descartes has no single, underlying principle of life.
} 
the concept put forward by its immediate predecessor is inadequate, arbitrary, or just plain wrong, before offering an alternative concept of its own.

My claim here is that the reason all these purported concepts of life turn out to be so unsatisfying is that looking for a general, principled concept of life in Descartes is the wrong approach to start with $\left(\$_{3}\right)$. Since he is entirely clear that life (whatever it might be) does not pertain to thinking substance (Passions I/5; AT XI: 329), it cannot be reducible to pure thought. But because his material ontology lacks the resources to discriminate the living from the non-living, there is nothing in extended substance for life to be reduced to either. And, as Detlefsen points out $\left(25 ; 4^{-} \mathrm{I}\right)$, Descartes commits himself to the inscrutability of God, for good reasons (AT VII: 55, 374-5), thus making God unavailable to support a concept of life. There is nowhere in Descartes's ontology for a concept of life to reside.

The more suitable approach, then, is to think that Descartes does away with a concept of life (\$3.I). He does not reduce it to something material. He does not look to God's intentions. What he does is dissolve or eliminate the category. Rather than addressing his account of physiology to the nature of life itself, and to finding a material source for it, Descartes takes on the traditional phenomena of physiology (cardiac heat, respiration, nutrition, generation, etc.) one by one and provides a material explanation for each. These explanations do not afford the reconstitution of any general, univocal concept of life. Consequently, in the process, the concept is dissolved away. ${ }^{4}$ If I am right about this, it means that Descartes recognised something that Machery has far more recently proposed

\footnotetext{
${ }^{4} C f$. Wolfe, who argues that there was no early modern controversy over life because there was "no polarization between Life and non-Life" (2OII: 192). Descartes is, however, responding to a problem driven by a polarisation between life and non-life; it just turns out that this is a problem that arises with respect to a tradition he rejects (see $\$ 3.2$ ).
} 
for modern biology: that "the project of defining life is either impossible or pointless" (2OII: I45).

There are parallels between this reading of Descartes and eliminativist materialist positions with respect to the mind. In eliminative materialism, "thoughts," "beliefs," "mind states," etc. are merely the terms of folk psychology, and they fail to refer to anything real. That is, there is nothing to which they can be reduced. As such, neuroscience has no need to attempt to explain them (nor could it): mind states should be eliminated from the science, which should focus instead on physical brain states. In his landmark paper on the elimination of propositional attitudes, Paul Churchland concludes

[t]he propositional attitudes of folk psychology do not constitute an unbreachable barrier to the advancing tide of neuroscience. On the contrary, the principled displacement of folk psychology is not only richly possible, it represents one of the most intriguing theoretical displacements we can currently imagine

(I981: 90).

Similarly, doing away with the notion of life itself is, presumably, a productive displacement that gives Descartes new possibilities (such as pervasive iatromechanism) for his work on physiology and medicine.

There are several advantages to the "dissolutionist" reading. Most importantly, it makes sense of the complete absence of an attempt to work out a general concept of life anywhere in Descartes's work and correspondence (if the lack of a concept of life "would render incoherent" Descartes's work on physiology and medicine, as Detlefsen claims (forthcoming: 2), for him to ignore it as he does would be a significant oversight). It is also non-arbitrary, in a way that MacKenzie-style lists of necessary life-functions are not (see 
\$2.3). And it remains consistent with both Descartes's ontological and theological commitments.

On the other hand, it might appear difficult for the dissolutionist reading to make sense of Descartes's use of the term "life." This problem is dealt with in \$3.2. One answer may be that Descartes uses "life" as a folk term, without any strict definition. I argue, though, that most instances of Descartes's use of "life" are responses to the Aristotelian position, where the term is well defined. Descartes's intention is to show that all the phenomena associated with life in the Aristotelian system are explicable under his own; this does not entail a subscription to the category of life itself. Concerns about whether Descartes can allow disciplinary unity to biology ${ }^{5}$ in the absence of a concept of life are addressed in $\$ 3 \cdot 3$. There, I argue that Descartes has no particular need for a principled unification of the discipline, and that whatever unity it may have is provided not by life but by (human) medicine. This allows life itself to be redundant for Cartesian biology.

\section{Concepts of life}

\section{I Cardiac heat}

Although Descartes never provides a general definition of life, he does frequently associate life with heat. For instance, he writes to Mersenne,

\footnotetext{
5 The term is anachronistic, of course, but efficient.
} 
[b]ut as to why you say that we cannot explain this phenomenon while allowing no principle of life other than beat to animals, it seems to me, on the contrary, that we could explain it better in no other way; given that heat is a common principle for animals, plants, and other bodies, it is no surprise that it should serve to make humans and plants live

(AT III: I22; my emphases).

So heat makes humans, plants, and animals live. But whatever Descartes might take life to be, it cannot come down to heat alone. This is because, as Descartes puts it, heat is a principle common to not just humans, animals, and plants, but also to "other bodies." That is, heat is also a principle of inorganic bodies. ${ }^{6}$ There are plenty of things in the natural world that are both warm and clearly non-living. Consequently, there is nothing about heat in itself that distinguishes between living and non-living. So if Descartes has a concept of life, and if that concept involves heat, it must involve heat in addition something else.

That something else would appear to be the heart. Descartes makes various seemingly straightforward statements such as "I do not deny life to animals, since I regard it as consisting simply in the heat of the heart" (to More, 5 February i649; CSMK: 366; AT V, 278). Elsewhere, he appears to identify cardiac heat as the principle of life (AT VI: 46; AT XI: 2O2; AT XI: 333). When Descartes appeals to this principle of life, and when he claims that life consists in cardiac heat, it certainly looks like a reduction of the concept of life to a material process. ${ }^{7}$ This would suggest that his concept of life is the following. ${ }^{8}$

\footnotetext{
${ }^{6} \mathrm{It}$ is central to Descartes's argument to Mersenne here that prevalence of heat as a motive force in inorganic phenomena is good reason to think it plays a role in organic phenomena too.

${ }^{7}$ Cardiac heat is generated entirely mechanically and materially on Descartes's account. See Fuchs 2OoI, part D.I for a detailed description.
} 


\section{Life $_{\mathrm{CH}}:=$ the possession of a warm heart}

There is an obvious problem with taking Life ${ }_{\mathrm{CH}}$ to be Descartes's concept of life: we want to describe plants as living, but would not want to attribute warm hearts to them. ${ }^{9}$ In addition, Descartes is quite clear that cardiac heat alone is not sufficient for life:

the tiny heart of an eel, which I cut out before seven or eight o'clock this morning, revives when a little heat is applied to its surface, and begins to beat again quite rapidly, even though it is obviously dead

(23 March I638; CSMK: 95; AT II: 66; my emphasis).

In this case, the heart is warm (and even beating) but nevertheless does not qualify as living. ${ }^{\text {IO }}$ Cardiac heat, therefore, cannot be not sufficient for life on Descartes's account. Consequently, if Descartes has a concept of life, it cannot be Life $\mathrm{CH}_{\text {. }}$

\subsection{Cardiac heat plus an ensemble of life-functions}

When we say that Life $\mathrm{CH}_{\mathrm{H}}$ cannot be Descartes's concept of life, the objection that immediately springs to mind is that cardiac heat might not be sufficient by itself but could still be necessary when buttressed by some other condition for life. In this case, the

\footnotetext{
${ }^{8}$ This seems to be the concept of life presupposed in Bitbol-Hespériès 1990 (see especially 40 and 96 ). Life $\mathrm{CH}_{\text {is also }}$ endorsed (although only in passing) by Canguilhem ([1965] I980: III).

${ }^{9}$ In a letter to Mersenne, Descartes attributes heat to the life of plants (30 July I64O; AT III: I22), but not hearts. See p. 7 above. Ablondi (I998: I83) cites a passage from the Cogitationes as more evidence for the same, although Descartes's concern there is with the role of heat for the development of plants and animals rather than for life itself.

Io An alternative reading of this passage might claim that the heart really does come back to life (the use of "revives" (reviviscere) would support that reading). However, from the context, it is clear that Descartes's aim is to show that the phenomenon of the heartbeat can be reproduced at a point after an Aristotelian would say the soul has left the body.
} 
reduction of life would be to cardiac heat plus one or more other material processes. This appears to be Hall's approach to the Cartesian concept of life:

Life $_{\mathrm{H}}:=$ "an ensemble of functions that have their kinetic origin in heat - specifically a certain 'fire without light' that burns, in men and animals, in the heart” (Hall r970: 6r).

Life $_{H}$ deals nicely with the case of the dead-but-warm eel heart: the eel heart is dead because it is not acting as the source of movement for some ensemble of functions. If the eel's warm heart were instead driving its life functions, it (or, rather, the eel) would be alive. Hall does not identify these functions, leaving $\mathrm{Life}_{\mathrm{H}}$, as it stands, somewhat vague. But the principle behind it is straightforward: life is not simply the heat of the heart, but a group of lifefunctions that are driven by the heat of the heart. It is the combination of cardiac heat with the ensemble of functions that is meant to provide sufficiency to the concept. In this case, it does not matter too much exactly what the functions are: they are life functions precisely because they are driven by the heat of the heart that is unique to living bodies. The lifefunctions are necessary here just because cardiac heat alone is insufficient for life, but it is still cardiac heat that does the bulk of the work in Life $\mathrm{H}_{\mathrm{H}}$.

The immediate problem is that Life $_{\mathrm{H}}$, in this form, would rule out plant life (because plants do not have hearts) - and Descartes seems to be just as willing to ascribe life to plants as to animals. In both the Principles (4:I88; AT VIIIA: 315) and the Description of the Human Body (AT XI: 247), he glosses "living things" as both plants and animals, and in the conversation with Burman, Descartes mentions prolonging the lives of plants as a model for prolonging human life (AT V: I78). If we want to find a concept of life in Descartes, the basic form of Life $_{\mathrm{H}}$ is evidently going to be too exclusive. 
There might be some traction in generalising the definition by omitting the specification after the dash in Hall's formulation:

Life $_{\mathrm{H}_{2}}:=$ an ensemble of functions that have their kinetic origin in heat.

This obviates the need to refer to the heart itself. And since there is at least one instance in which Descartes claims that plants too are driven by heat (AT III: I22), Life $\mathrm{H}_{2}$ is inclusive enough to account for plant life. However, without the restriction of specifically cardiac heat and its fire without light, the concept becomes too inclusive. Take, for example, the heating and water-boiling functions of a stove. They have their kinetic origin in heat. ${ }^{\text {II }}$ If we want an overarching concept of life, presumably we want it to exclude stoves while including plants. Since heat as kinetic origin is not specific enough to provide that restriction, it makes sense to look to the functions themselves: if it is only certain functions that are life-functions, and if water-boiling and heating are not on the list, the concept can effectively exclude stoves while including humans, animals, and plants. In the next section, I look at how MacKenzie builds on exactly this basis in attempting to specify a Cartesian concept of life (I975: 4).

\subsection{A list of life-functions}

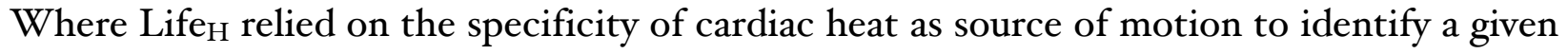
function as a life-function, MacKenzie explicitly moves the burden of specification to the functions themselves:

[t]he principle of motion in plants and animals without hearts will be that which (together with proper structure) enables them to engage in those determinate activities which in turn enable them to perform their life

\footnotetext{
${ }^{\text {II }}$ Heating is always kinetic for Descartes. See The World, part I, ch. 2 (AT XI: ${ }^{-}{ }^{-}$) $)$.
} 
functions. [. . .] Although all living creatures perform the same set of life functions, because of the vast set of differences among animate creatures, the determinate activities that enable them to perform the life functions differ

(MacKenzie 1975: I0).

This is a straightforward reversal of the hierarchy in Life $\mathrm{H}_{\mathrm{H}}$. The life-functions are constant, but the activities that produce them can differ-in some cases, it will be cardiac heat that drives the life-functions, and in others it will be something else. On MacKenzie's reading, rather than doing the bulk of the work in defining life, cardiac heat gets to be involved in life only if it produces life-functions. It is the functions themselves that do the work. Indeed, activities such as cardiac heat will figure in MacKenzie's definition only in the general stipulation that they be mechanical and material, so as to rule out psychistic principles of life (I975: 6).

The functions MacKenzie identifies as life-functions are simply nutrition, growth and generation (I975: 8). Accordingly, her (explicitly stated) definition is

Life $_{M K}:=$ " $x$ is alive if and only if $x$ has an arrangement of parts which (together with motion) enables $\mathrm{x}$ to gain nourishment from its environment, to grow, and to reproduce" (I975: 8).

In this definition, cardiac heat has been generalised to an arrangement of parts plus motion, which is inclusive enough to allow life to humans, animals, and plants, as well as to any other living thing that might happen to operate in a different manner. It rules out psychistic explanations via the suppressed assumption that parts are necessarily material. According to Life $_{M K}$, anything, heartless or not, will count as alive as long as it gains nourishment from its environment, grows, and reproduces. In this case, Life $_{M K}$ is meant to reduce life to a set of processes (life-functions) that are material by virtue of the arrangement-of-parts prescription. 
Since the three life-functions are doing the work in Life ${ }_{M K}$, we would expect them to be robustly specified and well grounded. If we are to rely on nutrition, growth and generation in order to determine what is alive and what is not, presumably we ought to be reasonably sure that nutrition, growth and generation are the right functions to use. Curiously, this is not what happens. MacKenzie tells us, "I can only speculate as to which functions Descartes would include on his list" (I975: 8), and readily acknowledges that the nutrition-growthgeneration list itself "may be incorrect" (I975: 8, n. I6). Her point is that some particular list will do the job, and that it is not necessary to specify it accurately in order to show that Descartes's conception of life will look like Life ${ }_{M K}$ (with a better list substituted if, in fact, appropriate): "a decision on precisely which functions Descartes would list is not necessary for a general understanding of Descartes' conception of life" (I975: 8, n. I6).

The first problem with $\mathrm{Life}_{M K}$ is that, with the life-functions doing the work, a decision on precisely which functions they are is entirely necessary for the concept to be meaningful. Without that decision, Life ${ }_{M K}$ becomes empty and arbitrary. With the list removed, Life $\mathrm{MK}_{\mathrm{K}}$ would read, " $\mathrm{x}$ is alive if and only if $\mathrm{x}$ has an arrangement of parts which (together with motion) enables $\mathrm{x}$ to perform some set of functions." This formulation would apply to any functioning machine; it only becomes specific to life when that set of functions is specified. Without the life-functions, Life ${ }_{M K}$ tells us nothing about life. In the absence of those functions, there is nothing for life to be reduced to. The second problem is that, as MacKenzie herself seems to be aware (I975: 8), there is no evidence that Descartes saw life in this way: he does not appeal to a set of functions as constitutive of life, and he does not seem to identify any particular function as constitutively necessary for life. As such, there is little to no scope for finding a set of functions in Descartes's work that can flesh out Life $\mathrm{MK}_{\mathrm{K}}$ and save it from vacuity. 


\subsection{Heat plus theogenic complexity}

Ablondi broadly accepts Life ${ }_{M K}$, but argues that a "more basic" criterion than a set of lifefunctions is available (I998: I83; emphasis in original). That more basic criterion is complexity. The main evidence for complexity as constitutive of life comes from the Treatise on Man:

[w]e see clocks, artificial fountains, mills, and other such machines which, although only man-made, have the power to move of their own accord in many different ways. But I am supposing this machine [the human body] to be made by the hands of God, and so I think you may reasonably think it capable of a greater variety of movements than I could possibly imagine in it, and of exhibiting more artistry than I could possibly ascribe to it

(CSM I: 99; AT XI: I2O).

In this passage, Descartes emphasises a difference between, on the one hand, manmade machines and, on the other, God-made machines capable of "a greater variety of movements" than is even imaginable by man (or at least by Descartes) and that display a greater level of craftsmanship than Descartes could ever attribute to them. The message is that we humans know what it is to make machines, but our clocks and fountains are monumentally crude in comparison to the machine of the human body made by God. It is not much of a stretch to see this as a distinction in complexity between living and non-living machines: living machines are significantly more complex than non-living ones. Hence, following the general format of both Hall's and MacKenzie's versions, Ablondi formulates a concept of life for Descartes as follows:

Life $_{A}:=$ "(I) possession of an internal source of heat which serves as a principle of motion, and (2) having the complexity which only God can give a thing" (Ablondi I998: I85). 
Ablondi presumably includes (I) so as to rule out complex theogenic artefacts we would not want to classify as living, such as vortices. He does not spell this out explicitly, but he does note that (2) is not sufficient by itself (I998: I85). On Ablondi's reading, given Descartes's few remarks about heat as their principle of life, plants are included by (I) (I998: I83); (2) is necessary so as to exclude heat-driven manmade automata (I998: I83).

It is significant that the complexity stipulated by (2) is the kind of complexity that only God can provide. For Ablondi, the difference in complexity between living and non-living machines cannot be a difference of degree. The difference is between what humans are capable of producing and what God is capable of producing, and "Descartes would be presuming clairvoyancy if he were to limit what human technology ever could do" (I998: I84)-i.e. if it were only a matter of degree, Descartes could not reasonably suppose that human technology would never be capable of reaching that degree. Consequently, while human bodies undoubtedly do have a higher degree of complexity than clocks, they must also have a different kind of complexity - a theogenic kind of complexity (I998: I84-5).

Ablondi himself recognises the problem with theogenic complexity:

there must be some recognizable feature flowing from this complexity which enables us to conclude that we can't produce things that complex. To say this feature is 'life' is to beg the question; the complexity of the thing has to be identifiable apart from its divine origin if the claim is to function as a genuine criterion

(I998: 184).

The trouble is that the mechanical complexity of the human body-machine exists entirely within the material world. The material world can accommodate different degrees of complexity perfectly well, in that we can give criteria for different degrees of complexity in 
material terms: more parts, smaller parts, more interactions between parts, etc. Material terms for the type of distinction in kind that Life $_{\mathrm{A}}$ requires are elusive. Descartes's ontology, which allows nothing but "shape, size, position and motion of particles of matter" (CSM I: 279; AT VIIIA: 3I4) in extended substance does not permit ontologically distinct kinds of material complexity. Ablondi notes that this problem is "quite damaging" (I998: I85) to Life $\mathrm{A}_{\mathrm{A}}$. His position appears to be that, although $\mathrm{Life}_{\mathrm{A}}$ is incoherent with respect to Descartes's system (i.e. it is not compatible with his commitments elsewhere), textual evidence suggests that it is nevertheless the conception of life that Descartes held.

I do not think, however, that the textual evidence bears out this conclusion. The evidence that Ablondi cites is sparse. Besides the passage from Man, there is a brief passage from the Discourse (in the context of a summary of the then-unpublished Man): "they will regard this body as a machine which, having been made by the hands of God, is incomparably better ordered than any machine that can be devised by man" (CSM I: I39; AT VI: 56). There is also a letter to More in which Descartes remarks, "since [. . .] people can make various automatons which move without thought, it seems reasonable that nature should even produce its own automatons, which are much more splendid than artificial ones - namely the animals" (5 February I649; CSMK: 366; AT V: 277). This is not especially conclusive. In none of these passages does Descartes indicate that greater complexity is constitutive of life, rather than being merely a contingent feature of animal and human bodies.

In the letter to More, Descartes is arguing against animal intelligence and is attempting to deflect the objection that animal behaviour is too close to intelligent human behaviour to be thoughtless. His strategy is to show that animal behaviour is on a continuum with that of manmade automata, rather than with human thought. It should not be too surprising, he reminds More, if natural automata happen to be noticeably more "splendid" (praestantiora) than their manmade equivalents. In summing up his argument, he explicitly tells More, 
"[p]lease note that I am speaking of thought, and not of life" (CSMK: 366; AT V: 278). Evidently, Descartes is not making the claim here that this splendidness is constitutive of life.

The passages from Man and the Discourse offer a little more support to Life ${ }_{\mathrm{A}}$, given their appeals to modality: the human body has "a greater variety of movements than I could possibly imagine in it" and exhibits "more artistry than I could possibly ascribe to it" (CSM I: 99; AT XI: I2O; my emphases); the human body is "incomparably better ordered than any machine that can be devised by man" (CSM I: I39; AT VI: 56; my emphasis). Taken literally, these comments do suggest that there is a kind of complexity that humans are incapable of ever producing, or even of ever imagining. It is not at all clear, however, that these comments should be taken literally. Descartes positions the Treatise on Man as a fable about a hypothetical mechanical human body that God could create. ${ }^{22}$ Even if the conclusions of the treatise are ultimately meant to transfer to the actual world, the passage quoted above is from the opening of the extant text, where the rhetoric of the fable is still being set up.

There is more here, then, to suggest that the modal claims are rhetorical appeals to the greatness of God (especially given Descartes's fears about the Inquisition's possible reaction to his World, of which Man is a part ${ }^{13}$ ) than that they are principled commitments to an ontologically distinct kind of complexity. Indeed, in a letter to Mersenne, Descartes explicitly makes the point that, metaphysically, we should be able to build an artificial bird, even if, "speaking as a physicist," we do not know how to make sufficiently intricate (subtils) springs (3O August I64O; AT III: $\mathrm{I}_{3}-4$ ): the problem is technical rather than ontological.

\footnotetext{
${ }^{12}$ See the editors' note in CSM I, p. 99, n. I.

${ }^{13}$ See to Mersenne, end of November i633 (AT I: 270-2).
} 
Furthermore, whatever the difference in complexity between living and non-living machines, Descartes gives us no reason to suppose that greater complexity is a necessary condition in defining life.

Lastly, the evidence that Ablondi cites is entirely concerned with human and animal bodies. Descartes never suggests that plants are more complex than we could possibly imagine. Of course, it is plausible that, if asked, Descartes would have replied that this applies to plants as much as it does to animals. But Ablondi's justification for attributing a concept of life to Descartes that is incoherent with his wider system is the textual evidence. And even on the most generous reading of the textual evidence for the relevance of theogenic complexity, plants are absent. On a textual basis, then, it would not be unfair to say that Life excludes plants, and as such, by Ablondi's own criteria, does not even provide a viable concept of life.

Life $_{\mathrm{A}}$ attempts to conceptualise life by reducing it to two things in the material world: (I) heat as an underlying source of motion plus (2) theogenic complexity. Theogenic complexity, however, is not definable in terms of matter. Ablondi is aware of this but thinks the textual evidence warrants attributing a concept of life to Descartes that is incoherent with his system. The incoherence alone would be enough to call for suspicion, but, as we have seen, the textual evidence itself also turns out to provide little support for Life . $_{\text {. }}$

\subsection{God's intentions}

The treatments of life we have looked at so far have all tried to find a concept of life through reduction to something in the material world. There are good reasons for this approach, given Descartes's repeated insistence that life pertains to extended substance, and not to thinking substance. Detlefsen, however, recognises that extended substance does not have the resources to sustain a concept of life; the purely material conditions will have to be shored up by something extramaterial. For Detlefsen, the extramaterial ingredient lies in 
God's intentions. Bringing in God to confer life circumvents the lack of appropriate resources in matter.

Detlefsen broadly accepts Life ${ }_{M K}$, but extends MacKenzie's list of life-functions to include reactivity to the environment as well as nutrition, growth, and generation, all subtended by another addition, a single overarching life-function: self-preservation (I9-2I). The following is, I think, a fair reconstruction of the concept of life that Detlefsen wants to allow Descartes, given her adjustments to Life $\mathrm{MK}_{\mathrm{M}}$ :

Life $_{\mathrm{D}}:=\mathrm{x}$ is alive if and only if $\mathrm{x}$ has an arrangement of parts which (together with motion) enables $\mathrm{x}$ to perform determinate life-functions (nutrition, growth, reproduction, and reactivity to the environment) for the sake of self-preservation.

Life $_{\mathrm{D}}$, as Detlefsen herself is well aware $(22,47)$, introduces teleology to the definition. The obvious culprit to blame for this intrusion of teleology is Life ${ }_{\mathrm{D}}$ 's reliance on selfpreservation (because self-preservation is the end the life functions serve). Interestingly, Detlefsen does not see self-preservation as the source of the teleology. On the basis of the arguments from Shapiro 2003 and Brown 20II, she takes self-preservation to be fairly straightforwardly non-teleological (I9, 23). Instead, she sees teleology entering the definition through the parts that perform the life-functions. Her example is the role of the mitral valve in Descartes's explanation of the heartbeat and its reliance on final causes (24). Consequently, even if self-preservation does escape teleology for Descartes (and I am somewhat less confident than Detlefsen that it does), teleology still creeps into Life $\mathrm{D}_{\mathrm{D}}$ if not from the top down through self-preservation itself, then from the bottom up through the life functions. 
Life ${ }_{\mathrm{D}}$ 's reliance on teleology is a problem. As Descartes keeps reminding us, whatever life is, it is entirely material (e.g. AT XI: 329-3I; AT III: 566), and activity occurs in matter (extended substance) exclusively through mechanical means (AT VIIIA: 54, 3I4). As such, matter can have no intrinsic ends, and the only recourse for teleology is through extrinsic ends. For manmade artefacts, extrinsic ends are easy to come by: a hammer is for hammering because someone designed it with that purpose. Similarly, for natural bodies, extrinsic ends would have to come from God: a heart is for pumping blood because God designed it with that purpose.

But Descartes rules out access to God's intentions and excludes them from any role in natural philosophy ${ }^{\mathrm{I}}$ : we are limited, while "the nature of God is immense, incomprehensible and infinite" and thus "capable of countless things whose causes are beyond my knowledge. And for this reason alone I consider the customary search for final causes to be totally useless in physics; there is considerable rashness in thinking myself capable of investigating the impenetrable ${ }^{15}$ purposes of God" (CSM II: $38^{8-9}$; AT VII: 55). ${ }^{\mathrm{I} 6}$ Even if God did provide natural bodies with extrinsic ends, we could never know about it, making it useless for explaining the natural world. In this case, God's intentions can tell us nothing about what life is just because we have no way of knowing what his intentions are.

Detlefsen offers an ingenious potential solution to the problem of inscrutability: it does not matter if we cannot have certain knowledge of God's intentions, because a well-supported

\footnotetext{
${ }^{\mathrm{I}}$ Given Descartes's insistence that what we think of as the life of humans and animals pertains to extended substance, life pertains to natural philosophy (if there is such a thing as life).

${ }^{15}$ The use of "impenetrable" here is an addition in the I647 French translation approved by Descartes (AT XIa: 44).

${ }^{16}$ See also AT VII: $374^{-5}$ and AT VIIIA: 15-16.
} 


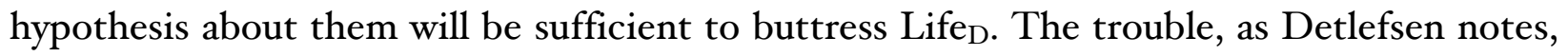
is that even hypothesising about God's intentions is off limits for Cartesian natural philosophy:

from Descartes' point of view, what I suggest above is illegitimate; we cannot use teleological explanations in so far as they are grounded in claims about God's purposes even as merely likely true beliefs in our explanations about the natural world, and so we cannot explain the teleological nature of (at least some) life activities by relying upon hypothetical claims to God's purposes as embodied in (at least some) living bodies

(Detlefsen: 48).

Detlefsen argues that, without a concept of life, Descartes would have no way to identify living bodies as the subject of the life sciences, which "would render incoherent" his work on biology (2). She takes Life ${ }_{D}$ to be that concept, but notes that Descartes maintains his metaphysical commitment to the inscrutability of God's intentions rather than adopting Life $_{\mathrm{D}}\left(48^{-50}\right.$ ). Like Ablondi, Detlefsen upholds the need for a principled conception of life at the expense of the coherence of Descartes's larger system. Ablondi preserves Descartes's biology to the detriment of his metaphysics, in his claim that the textual evidence shows that Descartes holds Life $_{A}$ despite its incompatibility with his ontology. Detlefsen preserves Descartes's metaphysics to the detriment of his biology: retaining the inscrutability of God's intentions in the light of Life $\mathrm{D}_{\mathrm{D}}$ makes Descartes's biology incoherent.

We do not need to force Descartes into such pessimistic outcomes. In the following section, I argue that the problem with Descartes's conception of life is not just with the proposed conceptions themselves - it is, first and foremost, with the expectation that he have one. 


\section{Descartes and the dissolution of life}

\section{I Dissolution}

The readings of Descartes discussed above have all focused on the need to attribute him with a principled means of distinguishing the living from the non-living. Each attempt to do so results in either an unworkable concept of life or a strong concept with destructive consequences. Life $\mathrm{CH}_{\mathrm{H}}$ was insufficient. $\mathrm{Life}_{\mathrm{H}}$ was too exclusive to be viable. Life $\mathrm{MK}_{\mathrm{K}}$ was too arbitrary and resulted in vacuity. Both $\operatorname{Life}_{\mathrm{A}}$ and Life $\mathrm{D}_{\mathrm{D}}$ ended up imposing incoherence on Descartes's philosophy. This is not an exhaustive list, and there may well be other possible answers to the question of what life is for Descartes. It seems likely, however, that there is something wrong with the question.

The trouble is that there is nowhere for the category of life to comfortably reside in Descartes's ontology. He strenuously rejects its presence in thinking substance. Whenever he mentions life, he attributes it to extended substance. But extended substance is homogeneous: there is no material difference between a human body and a grain mill. Attempts to identify aspects of matter that pertain specifically to living things lead to arbitrariness and fall apart swiftly (as with $\mathrm{Life}_{\mathrm{CH}}, \mathrm{Life}_{\mathrm{H}}$ and Life $\mathrm{MK}_{\mathrm{K}}$ ) precisely because there is nothing in matter that can make it belong to living things rather than non-living things. Matter is matter for Descartes, whether arranged into a clock or into an animal. If thought and matter are both ruled out, then seemingly the only recourse for a concept of life is in God's intentions. Unfortunately, God's intentions are off limits for Cartesian natural philosophy: if that is where the definition of life resides, then it is forever hopelessly out of reach. It seems that wherever we look for the category of life in Descartes's ontology, we will reach an impasse.

The solution to the above problems is to not look for a principled concept of life. Descartes provides no general, rigorous definition of life because he does not have one. And it is not 
that he has no such concept because his philosophy is incoherent. It is because he does not need one: a concept of life as such plays no role in his biology or in his wider system, and its absence is entirely without detriment. Descartes's aim is not to provide a concept of life, but to explain life away. Hall makes the point that "the explanations [Descartes] developed were corpuscularized, nonpsychistic versions of psychistic explanations put forth earlier by others" (I968: 63; italics removed). ${ }^{17}$ His method in biology was not to produce "explanations of fact" but explanations of "other peoples' explanations (often dismembered and reassembled with various additions and deletions)" (I968: 64; italics removed). ${ }^{\mathrm{I}}$ The evidence bears this out. Descartes takes on the Aristotelian psychistic conception of life, and he indeed dismembers and reassembles it differently, with additions and deletions. In other words, he breaks the Aristotelian conception apart and demonstrates piecemeal how each of the functions it performs can be produced by nonpyschistic, mechanical interactions of matter. Nutrition, for Descartes, is identical to the accretion of blood particles in the pores of the organs (AT XI: 245-52). The animation of the body is driven by the heat of the heart and the various mechanical processes (respiration, circulation, digestion, etc.) that feed into it (Passions I:8; AT XI, 333). It is through the explanation of the various phenomena traditionally associated with life that Descartes deals with life.

\footnotetext{
${ }^{17}$ This is perhaps a good way of understanding Descartes's defensive remark to Plempius, on having been accused of merely replicating Aristotle's account of the cause of the heartbeat: "If two people arrive at the same place, the one taking the right road, the other the wrong one, we ought not to think that the former is following in the footsteps of the latter" (I5 February I638; CSMK: 80; AT I: 522).

${ }^{\text {I } 8}$ This is not to suggest that Descartes made no innovations. Hall's point is that the problems Descartes addressed were taken from the established treatments of biology, rather than directly from nature; his answers to those problems were (largely) his own.
} 
In Cartesian reduction, there is an analytic step followed by a synthetic step. The phenomenon at hand is broken down into its most basic parts, and then the original phenomenon is reconstructed from those basic parts (AT X: 379-87). A reductive explanation is able to synthesise the phenomenon it explains from the parts to which the phenomenon has been reduced. This is precisely what Descartes does with nutrition, animation, sensation, etc. If nutrition is explained as accretion of blood particles in organ pores, you have nutrition exactly when you have accretion of blood particles in organ pores. This is not, however, what Descartes does with life. When it comes to life, as the previous sections of this paper have shown, the category cannot be reconstituted from the material, mechanical explanations of the life-phenomena. As we have seen, if we have cardiac heat, nutrition, etc., we still cannot reliably distinguish living things from non-living things. Descartes does perform the analytic step for life: as outlined above, he reduces everything the Aristotelian conception associated with life to mechanical interactions of matter. But he does not perform the synthetic step (because he cannot). In this sense, Descartes is not a reductionist about life but a strict eliminativist. In the process of analysing life-phenomena, Descartes simply dissolves the category of life itself.

\subsection{Objection: Descartes talks about life}

If Descartes dissolves the category of life, then why does he continue to talk about life in all the ways outlined in \$r? He is certainly not averse to using the term, and his use of it does seem to be meaningful. There are several possible replies to this objection. One is simply to suggest that, compared to the loss of the coherence of either metaphysics or biology that strong reductionist positions about Descartes's conception of life seem to result in, the occasional use of a term with no strict, principled definition seems like a minor infraction, especially if nothing of much significance rests on it (see $\$ 3.3$ below). This is a fairly reasonable response, but it is not particularly satisfying. A better variation would be to claim that "life," in this context, is something like a folk term. Just as a strict physicalist might 
sometimes find it more convenient to talk about desires rather than the specific brain-states desires reduce down to, so Descartes finds it more convenient to talk about a living animal rather than a non-manmade automaton with whatever attributes and behaviours happen to be relevant to the particular automaton in question. ${ }^{19}$

A stronger variation on this latter response would point out that "life" is not just a folk term for Descartes: it is an Aristotelian term. In almost every instance where Descartes refers to life, he is explicitly trying to demonstrate the distinction between his own biology and Aristotelian psychistic biology. When Descartes brings up life in both the Treatise on Man and the Discourse, it is expressly to point out the redundancy of vegetative and sensitive souls (AT XI: 202; AT VI: 45-6). When he does the same in articles five and six of The Passions of the Soul, it is to show that taking the soul to animate the body (i.e. the Aristotelian position) is a "very serious error" (CSM I: 329; AT XI: 330). Similarly, the discussion of the heartbeat in the correspondence with Plempius is in response to Aristotelian objections from both Plempius and (initially) Fromondus (AT I: 4I3-6; AT I: 52I-34; and especially AT II: 62-9). Descartes does not, then, use the term "life" because it is well-defined in the Cartesian system but because it is well-defined in the Aristotelian system-and his aim when using the term is to show that all the phenomena an Aristotelian will associate with life are mechanistically explicable. ${ }^{20}$

\footnotetext{
${ }^{19}$ Wolfe (2OIO: 204) discusses instrumental uses of the term "organism" in modern biology in much the same way.

${ }^{20}$ Somewhat similar aims crop up throughout Descartes's natural philosophy, of course. In the explanation of fire in the World, e.g., Descartes makes a point of how his mechanics can account for just as much as an Aristotelian "form of fire" and "quality of heat," while being both more explanatory and less ontologically extravagant (CSM I: 83; AT XI: 7-9).
} 


\subsection{Objection: Descartes's biology needs a principled concept of life}

One of Detlefsen's major concerns with respect to Descartes's concept of life is that, without a principled concept, Descartes could not identify life; and without life, he could have no life sciences, despite his deep commitment to anatomy, physiology and medicine (2). It is this concern that, given Life $e_{\mathrm{D}}$, leads Detlefsen to the pessimistic conclusion that Descartes's life sciences are bankrupt $(\$ 2.5$ above). If Descartes does indeed require a principled concept of life to demarcate the discipline of biology, then the dissolutionist reading will also lead Descartes's project into incoherence.

However, Descartes's concerns are not those of modern life sciences. Unlike today's science, Descartes had no particular need to protect the disciplinary unity of general biology. For Descartes, little would be at risk if the "life sciences" were to entirely collapse into physics. Nor did he have any need for a biology capable of dealing with all living things, given that he was always perfectly clear that his ultimate aim was $\left(\right.$ human ${ }^{21}$ ) medicine (AT IV: 329; AT VI: $62-3$; AT VI: 78 ). ${ }^{22}$ Consequently, it is not life itself that gives unity to this "aspect of his life as a working natural philosopher" (Detlefsen: 2); it is the potential of physiology and anatomy for the medical treatment of humans. And since humans are not just bodies but unions of soul and body, teleology is not a problem for (human) medicine: medicine can legitimately be an end for the Cartesian natural philosopher's pursuit of biology. Life itself, then, is not necessary for constituting the discipline of biology for Descartes. Consequently, dissolutionism about life is not a problem for Cartesian biology.

\footnotetext{
${ }^{2 \mathrm{I}}$ Descartes is famously antipathetic towards animal welfare. Veterinary medicine would be a literal oxymoron for him. See to More, 5 February I649 (AT V: 278-9). But cf. Harrison I992.

${ }^{22}$ On the centrality of medicine in Descartes's philosophy, see especially Aucante 2006, and Manning's (2007) extended review of the same.
} 


\section{Conclusion}

Initially, there appear to be good reasons for taking Descartes to be a reductionist about life, and for thinking that there is a well-defined, principled concept of life to be found in his philosophy. However, attempts to find such a concept result in insufficiency and inviability $\left(\mathrm{Life}_{\mathrm{CH}}, \mathrm{Life}_{\mathrm{H}}\right.$ ) or arbitrariness ( $\mathrm{Life}_{\mathrm{MK}}$ ), or they push Descartes's system into incoherence ( $\operatorname{Life}_{\mathrm{A}}, \mathrm{Life}_{\mathrm{D}}$ ). This is because there is nothing in Descartes's ontology for life to be reduced to: it is not a species of thought, extended substance lacks the resources for distinguishing living from non-living, and God's intentions are inscrutable. The alternative is to relinquish the requirement for a well-defined, principled concept of life. Rather than being a reductionist about life, Descartes dissolves the category. The dissolutionist reading makes good sense of Descartes's unwillingness to produce, or even to discuss, a general definition of life, and, unlike the alternatives, it appears to have no negative repercussions for Descartes's system. ${ }^{23}$

\footnotetext{
${ }^{23}$ Many people have helped improve this paper, amongst whom I owe particular thanks to Peter Anstey, Boris Demarest, Dennis Des Chene, Daniel Garber, Laura Georgescu, Alex Levine, Eric Schliesser, Daniel Schneider, Charles Wolfe, and the anonymous referees at the Southern Journal of Philosophy. I'm also especially grateful to Karen Detlefsen for sharing her forthcoming paper with me, and for granting permission to cite it here.
} 


\section{References}

Ablondi, Fred. "Automata, living and non-living: Descartes' mechanical biology and his criteria for life." Biology and Philosophy г3 (1998): 179-186.

Aucante, Vincent. La philosophie médicale de Descartes. Paris: Presses Universitaires de France, 2006.

Bitbol-Hespériès, Annie. Le principe de vie chez Descartes. Paris: J. Vrin, 1990.

Brown, Deborah. "Cartesian functional analysis." Australasian fournal of Philosophy 90/I (2OII): $75^{-92 .}$

Canguilhem, Georges. "Machine et organisme." In Georges Canguilhem, La Connaissance de la vie, IOI-27. Paris: J. Vrin, [1965] 1980.

Churchland, Paul. "Eliminative Materialism and the Propositional Attitudes." The fournal of Philosophy 78/2 (198I): 67-90.

(CSM) Descartes, René. The philosophical rwritings of Descartes. Edited and translated by John Cottingham, Robert Stoothoff and Dugald Murdoch. 2 vols. Cambridge: Cambridge University Press, 1984 and 1985.

(CSMK) Descartes, René. The philosophical writings of Descartes: The correspondence. Edited and translated by John Cottingham, Robert Stoothoff, Dugald Murdoch and Antony Kenny. Cambridge: Cambridge University Press, I99I.

(AT) Descartes, René. Oeuvres de Descartes, Edited by Charles Adam and Paul Tannery. II vols. Paris: J Vrin, 1996. 
Des Chene, Dennis. Spirits \& clocks: Machine \& organism in Descartes. Ithaca, NY: Cornell University Press, 200I.

Detlefsen, Karen. "Descartes on the Theory of Life and Methodology in the Life Sciences." In Early Modern Medicine and Natural Philosophy, edited by Peter Distelzweig, Benjamin Goldberg and Evan Ragland. Dordrecht: Springer, forthcoming.

Distelzweig, Peter. "The Uses of Usus and the Function of Functio: Teleology and its Limits in Descartes' Physiology." Fournal of the History of Philosopby 53/3 $(2015): 377^{-99}$.

Fuchs, Thomas. The mechanization of the heart: Harvey and Descartes. Translated by Marjorie Grene. Rochester, NY: University of Rochester Press, 200 I.

Hall, Thomas Steele. "Descartes' physiological method: Position, principles, examples." Fournal of the History of Biology 3/I (I970): 53-79.

Harrison, Peter. "Descartes on Animals." The Philosophical Quarterly 42/167 (I992): 219-227.

Hutchins, Barnaby. "Descartes, Corpuscles and Reductionism: Mechanism and Systems in Descartes' Physiology." The Philosophical 2uarterly (forthcoming a).

Hutchins, Barnaby. "Does Descartes have a principle of life? Hierarchy and interdependence in Descartes's physiology." Perspectives on Science (forthcoming b).

Machery, Edouard. "Why I stopped worrying about the definition of life... and why you should as well." Synthese I85 (2012): I45-164. 
MacKenzie, Ann Wilbur. “A Word about Descartes' Mechanistic Conception of Life.” Fournal of the History of Biology I8/I (I975): $\mathrm{I}^{-} \mathrm{I} 3$.

Manning, Gideon. "Out on the Limb: The Place of Medicine in Descartes' Philosophy." Early Science and Medicine I2 (2007): 214-222.

Shapiro, Lisa. "The health of the body-machine? Or seventeenth century mechanism and the concept of health." Perspectives on Science II/4 (2003): 42I442.

Simmons, Alison. "Sensible Ends: Latent Teleology in Descartes' Account of Sensation.” Fournal of the History of Philosophy 39/I (2001): 49-75.

Wolfe, Charles. "Do Organisms Have An Ontological Status?” History and Philosophy of the Life Sciences 32 (2010): 195-232.

Wolfe, Charles. "Why was there no controversy over Life in the Scientific Revolution?.” In Controversies Within the Scientific Revolution. Edited by Marcelo Dascal and Victor D Boantza, I87-219. Amsterdam/Philadelphia: John Benjamins Publishing Company, 2OII. 